\title{
Synthesis of diverse dihydropyrimidine-related scaffolds by fluorous benzaldehyde-based Biginelli reaction and post-condensation modifications
}

Bruno Piqani and Wei Zhang*

\author{
Letter \\ Address: \\ Department of Chemistry, University of Massachusetts Boston, 100 \\ Morrissey Boulevard, Boston, MA 02125, USA \\ Email: \\ Bruno Piqani - piqani@gmail.com; Wei Zhang* - \\ wei2.zhang@umb.edu \\ ${ }^{*}$ Corresponding author \\ Keywords: \\ Biginelli reaction; dihydropyrimidine; diversity-oriented synthesis; \\ fluorous; Suzuki coupling
}

Beilstein J. Org. Chem. 2011, 7, 1294-1298.
doi:10.3762/bjoc.7.150

Received: 10 June 2011

Accepted: 23 August 2011

Published: 16 September 2011

This article is part of the Thematic Series "Multicomponent reactions".

Guest Editor: T. J. J. Müller

(c) 2011 Piqani and Zhang; licensee Beilstein-Institut. License and terms: see end of document.

\begin{abstract}
Dihydropyrimidinones and dihydropyrimidinethiones generated from the Biginelli reactions of perfluorooctanesulfonyl-attached benzaldehydes are used as common intermediates for post-condensation modifications such as cycloaddition, Liebeskind-Srogl reaction and Suzuki coupling to form biaryl-substituted dihydropyrimidinone, dihydropyrimidine, and thiazolopyrimidine compounds. The high efficiency of the diversity-oriented synthesis is achieved by conducting a multicomponent reaction for improved atom economy, under microwave heating for fast reaction, and with fluorous solid-phase extractions (F-SPE) for ease of purification.
\end{abstract}

\section{Introduction}

Dihydropyrimidinone and dihydropyrimidine derivatives have broad biologically activities. Many synthetic samples have been studied as antibacterial, antiviral, antihypertensive, and anticancer agents [1], and the natural products containing these heterocyclic moieties have been studied as new leads for AIDS therapies [2]. The Biginelli reaction of a $\beta$-keto ester, an aldehyde, and urea is considered as one of the most efficient ways to synthesize dihydropyrimidinones [3]. This acid-catalyzed reaction can be conducted under conventional or microwave heating $[4,5]$. Reported in this paper is a diversity-oriented synthesis of biaryl-substituted dihydropyrimidinone 5, thiazolopyrimidine 6, and dihydropyrimidine 7 compounds (Scheme 1). The perfluorooctanesulfonyl-attached benzaldehydes $\mathbf{1}$ were used as a key component for the Biginelli reactions [6]. The Biginelli products 4 were used as a common intermediate for post-condensation reactions including cycloaddition, Liebeskind-Srogl reaction and Suzuki coupling to form three different heterocyclic skeletons. The high efficiency of the 


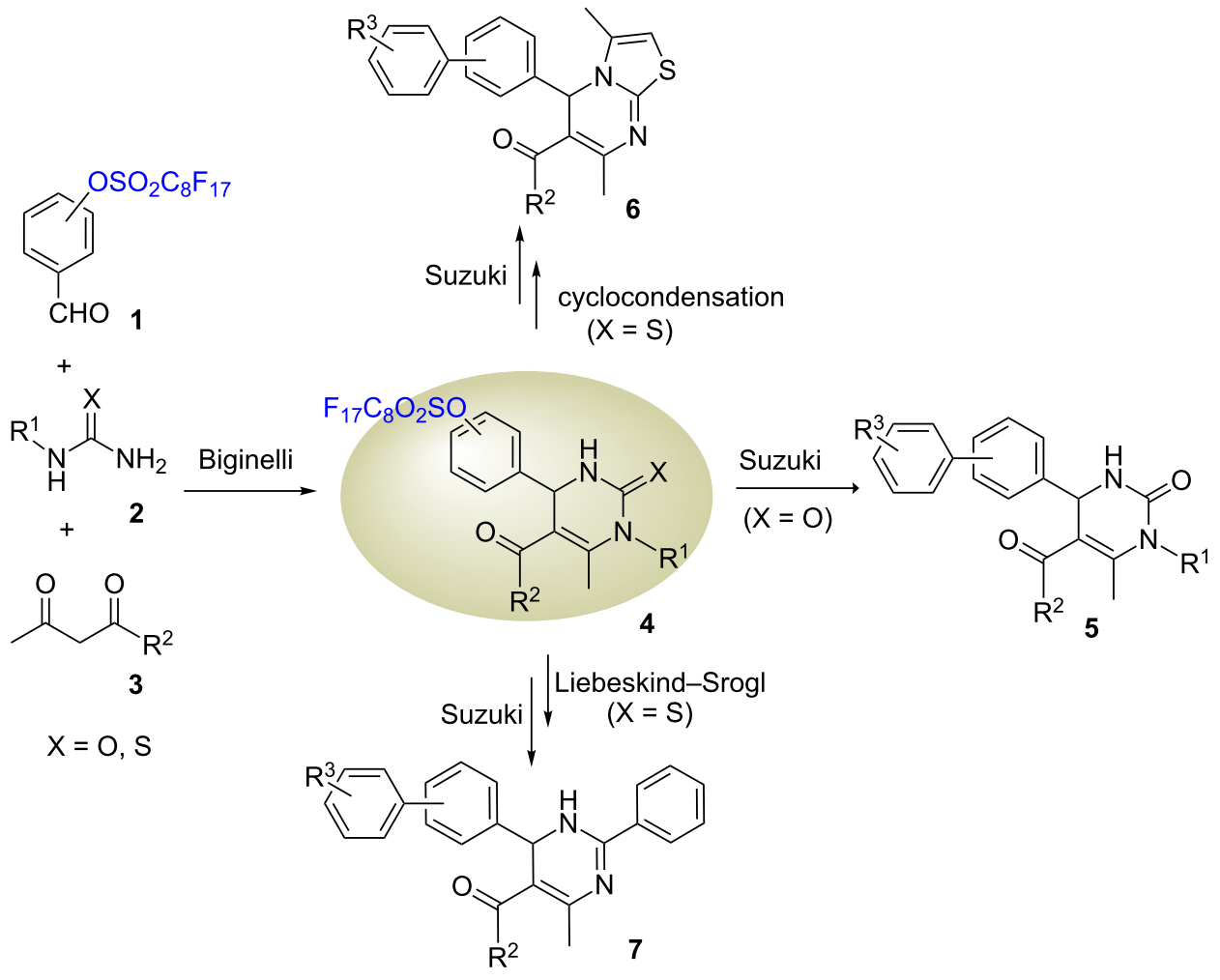

Scheme 1: Synthesis of diverse dihydropyrimidine-related compounds.

diversity-oriented synthesis was achieved by conducting fast, microwave-heated reactions and simple fluorous solid-phase extractions (F-SPE) for purification [7]. The perfluorooctanesulfonyl group served as a phase tag for F-SPE and also as a convertible linker for the Suzuki coupling to introduce biaryl functionality to the heterocyclic skeletons [8-12].

\section{Result and Discussion}

Fluorous benzaldehydes 1 were prepared by the reaction of phenols with perfluorooctanesulfonyl fluoride, by following the reported procedure [13]. Compounds 1 were used as a limiting agent to react with urea/thiourea $\mathbf{2}$ and acetylacetone $\mathbf{3}$ for the Biginelli reactions. The reactions were promoted by $\mathrm{Yb}(\mathrm{OTf})_{3}$ as a catalyst $[14,15]$, acetonitrile as a solvent, and under microwave irradiation at $120^{\circ} \mathrm{C}$ for $20 \mathrm{~min}$. This optimized condition was developed after other solvents, including water, EtOH and toluene, and different microwave reaction temperatures $\left(100-130^{\circ} \mathrm{C}\right)$ and times $(10-20 \mathrm{~min})$ were explored. The Biginelli products were separated from the reaction mixtures by F-SPE eluted with fluorophobic $80: 20 \mathrm{MeOH} / \mathrm{H}_{2} \mathrm{O}$ and then fluorophilic $100 \% \mathrm{MeOH}$ or acetone [7]. The fluorous Biginelli products were collected from the $\mathrm{MeOH}$ fraction to give dihydropyrimidinones $\mathbf{4 a - d}$ and dihydropyrimidinethiones $\mathbf{4 e ,}, \mathbf{f}$ in $85-95 \%$ yields (Table 1). The Biginelli products $4 \mathbf{a}-\mathbf{e}$ were used for Suzuki coupling reactions to remove the fluorous linker and introduce the biaryl functional group. The coupling reactions were promoted by microwave heating at $140{ }^{\circ} \mathrm{C}$ for 30 min with $\mathrm{Pd}(\mathrm{pddf}) \mathrm{Cl}_{2}$ as a catalyst, $\mathrm{Cs}_{2} \mathrm{CO}_{3}$ as a base, and 4:4:1 acetone/toluene/ $\mathrm{H}_{2} \mathrm{O}$ as a solvent [13]. Dihydropyrimidinones $4 \mathbf{a}-\mathbf{d}$ gave the expected products $\mathbf{5 a}-\mathbf{h}$ in $51-68 \%$ yield after F-SPE and flash chromatography purification. However, no reactions occurred with the dihydropyrimidinethiones $4 \mathbf{e}, \mathbf{f}$ under these reaction conditions.

Since dihydropyrimidinethiones $\mathbf{4 e , f}$ failed to give Suzuki coupling products, our next effort was to convert them to thiazolopyrimidine through cyclocondensation with chloroacetone $[16,17]$. The reaction was performed in water under microwave heating at $120{ }^{\circ} \mathrm{C}$ for $30 \mathrm{~min}$ to afford thiazolopyrimidines $8 \mathbf{8}$ and $\mathbf{8 b}$ in $89 \%$ and $85 \%$ yields, respectively, after F-SPE. Suzuki reactions of $\mathbf{8 a}$ and $\mathbf{8 b}$ with four boronic acids yielded 5-biaryl-5H-thiazolo[3,2-a]pyrimidines $\mathbf{6 a - h}$ in 55-64\% yields after F-SPE and flash chromatography purifications (Table 2).

Dihydropyrimidinethione $\mathbf{4 f}$ was used for the Liebeskind-Srogl coupling reaction with a phenylboronic acid to convert to 2-aryl-1,6-dihydropyrimidine 9 [18-20]. The reaction was performed following a literature procedure [21] and was 
Table 1: Biginelli reactions followed by Suzuki reactions of dihydropyrimidinones and dihydropyrimidinethiones.<smiles>O=Cc1cccc(OS(=O)(=O)OC(F)(F)F)c1</smiles>

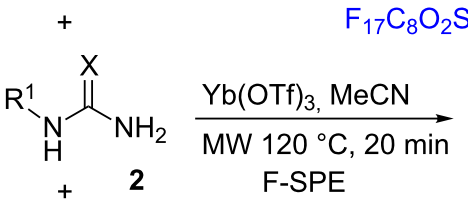<smiles>[R]C(=O)C1=C(C)N([R1])C([X])NC1c1ccccc1</smiles>

4<smiles>[R]C(=O)CC(C)=O</smiles>

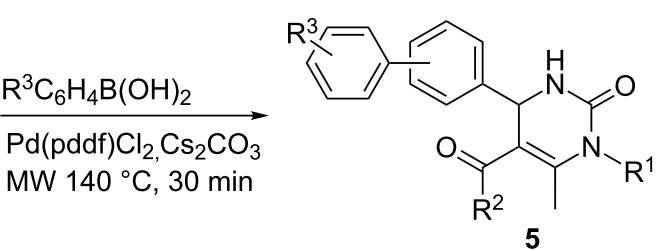

$\mathrm{Pd}($ pddf $) \mathrm{Cl}_{2}, \mathrm{Cs}_{2} \mathrm{CO}_{3}$
$\mathrm{MW} 140{ }^{\circ} \mathrm{C}, 30 \mathrm{~min}$

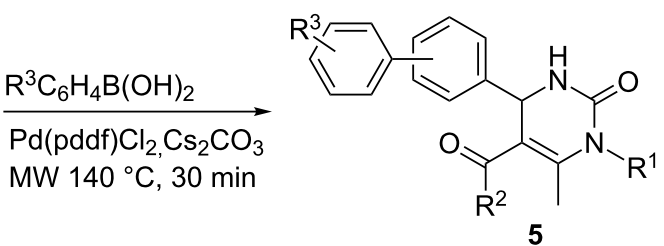

3

\begin{tabular}{|c|c|c|c|c|c|c|}
\hline $\mathrm{R}^{1}$ & $\mathrm{R}^{2}$ & $x$ & $\begin{array}{l}\text { F-Sulfonyl } \\
\text { position }\end{array}$ & 4 (yield) & $\mathrm{R}^{3}$ & 5 (yield) \\
\hline \multirow[t]{2}{*}{$\mathrm{CH}_{3}$} & $\mathrm{CH}_{3}$ & $\mathrm{O}$ & meta & $4 a(91 \%)$ & $p-\mathrm{OCH}_{3}$ & $5 a(67 \%)$ \\
\hline & & & & & $\mathrm{H}$ & $5 b(56 \%)$ \\
\hline \multirow{2}{*}{$\mathrm{CH}_{3}$} & $\mathrm{OCH}_{3}$ & $\mathrm{O}$ & meta & 4b (95\%) & $p-\mathrm{OCH}_{3}$ & $5 c(57 \%)$ \\
\hline & & & & & $\mathrm{H}$ & $5 d(51 \%)$ \\
\hline \multirow[t]{2}{*}{$\mathrm{CH}_{3}$} & $\mathrm{CH}_{3}$ & O & para & $4 c(90 \%)$ & $p-\mathrm{OCH}_{3}$ & $5 e(68 \%)$ \\
\hline & & & & & $\mathrm{H}$ & $5 f(62 \%)$ \\
\hline \multirow[t]{2}{*}{$\mathrm{CH}_{3}$} & $\mathrm{OCH}_{3}$ & O & para & 4d (88\%) & $p-\mathrm{OCH}_{3}$ & $5 g(58 \%)$ \\
\hline & & & & & $\mathrm{H}$ & $5 \mathrm{~h}(60 \%)$ \\
\hline $\mathrm{H}$ & $\mathrm{CH}_{3}$ & $S$ & meta & 4e $(89 \%)$ & $\mathrm{H}$ & - \\
\hline $\mathrm{H}$ & $\mathrm{OCH}_{3}$ & $S$ & meta & $\mathbf{4 f}(85 \%)$ & $\mathrm{H}$ & - \\
\hline
\end{tabular}

Table 2: Synthesis of biaryl-substituted thiazolopyrimidines.

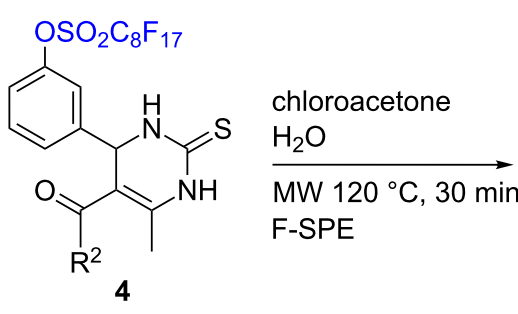

$\mathrm{H}_{2} \mathrm{O}$

4

$\mathrm{R}^{2}$

$\mathrm{CH}_{3}$

$4 f$

$\mathrm{OCH}_{3}$

8b $(85 \%)$<smiles>[R]C(=O)C1=C(C)N=C2SC=C(C(F)(F)F)N2C1c1cccc(O[R6]([H])([H])F)c1</smiles>

$\mathrm{R}^{3} \mathrm{C}_{6} \mathrm{H}_{4} \mathrm{~B}(\mathrm{OH})_{2}$

$\mathrm{Pd}$ (pddf) $\mathrm{Cl}_{2}, \mathrm{Cs}_{2} \mathrm{CO}_{3}$ $\mathrm{MW} 140{ }^{\circ} \mathrm{C}, 30 \mathrm{~min}$<smiles>[R]C(=O)C1=C(C)N=C2SC=C(C)N2C1c1cccc(-c2ccccc2)c1</smiles>

$\begin{array}{llll}\mathbf{4 e} & \mathbf{8 a}(89 \%) & \mathrm{H} & \mathbf{6 a}(61 \%) \\ & & p-\mathrm{OCH}_{3} & \mathbf{6 b}(64 \%) \\ & & m-\mathrm{Cl} & \mathbf{6 c}(56 \%) \\ & & p-\mathrm{CH}_{3} & \mathbf{6 d}(62 \%) \\ & & \mathrm{H} & \mathbf{6 e}(58 \%) \\ & \mathbf{8 b}(85 \%) & p-\mathrm{OCH}_{3} & \mathbf{6 f}(55 \%) \\ & & m-\mathrm{Cl}_{3} & \mathbf{6 g}(63 \%) \\ & & p-\mathrm{CH}_{3} & \mathbf{6 h}(55 \%)\end{array}$


catalyzed by $\mathrm{Pd}\left(\mathrm{PPh}_{3}\right)_{4}$ and copper(I) thiophene-2-carboxylate (CuTC) under microwave heating at $100{ }^{\circ} \mathrm{C}$ for $25 \mathrm{~min}$ to afford aryl-substituted dihydropyrimidine 9 in $76 \%$ yield. This compound was then subjected to Suzuki coupling reactions with four boronic acids to yield 2-aryl-6-biaryl substituted dihydropyrimidines $\mathbf{7 a - d}$ after F-SPE and flash chromatography purifications (Table 3).

\section{Conclusion}

We have developed a new application of perfluorooctanesulfonyl-attached benzaldehydes for the diversity-oriented synthesis of heterocyclic scaffolds. The intermediates obtained from the Biginelli reaction were used for post-condensation modifications to afford biaryl-substituted dihydropyrimidinone, dihydropyrimidine, and thiazolopyrimidine compounds. A set of reaction and separation techniques such as multicomponent reactions, microwave heating, and F-SPE was employed to increase the synthetic efficiency. The fluorous sulfonyl group not only served as a phase tag for F-SPE separation, but also as a cleavable linker for the Suzuki coupling reactions.

\section{Experimental}

Typical Biginelli reaction procedure: Synthesis of 5-acetyl-4-(4(perfluorooctylsulfonyloxy)phenyl)-1,6-dimethyl-3,4-dihydropyrimidin-2(1H)-one (4c)

A solution of $p$-perfluorooctanesulfonyl benzaldehyde 1 (1.2 g, $2.0 \mathrm{mmol})$, methylurea $2(0.18 \mathrm{~g}, 2.4 \mathrm{mmol})$, methyl acetoacetate $3(0.35 \mathrm{~g}, 3.0 \mathrm{mmol})$ and $\mathrm{Yb}(\mathrm{OTf})_{3}(124 \mathrm{mg}, 0.2 \mathrm{mmol})$ in $2 \mathrm{~mL}$ of acetonitrile was heated in a Biotage Initiator microwave synthesizer at $120^{\circ} \mathrm{C}$ for $20 \mathrm{~min}$. The resulting mixture was purified by F-SPE eluted with $40 \mathrm{~mL}$ of 80:20 MeOH/
$\mathrm{H}_{2} \mathrm{O}$ and then $40 \mathrm{~mL}$ of acetone. The acetone fraction was concentrated to give $4 \mathrm{c}(1.3 \mathrm{~g})$ in $90 \%$ yield.

Typical Suzuki reaction procedure: Synthesis of 5-acetyl-4-(4'-methoxy-[1,1'-biphenyl]-3-yl)-1,6dimethyl-3,4-dihydropyrimidin-2(1H)-one (5a)

A solution of 4a (75 mg, $0.1 \mathrm{mmol})$, 4-methoxyphenylboronic acid (23 mg, $0.15 \mathrm{mmol}), \mathrm{Cs}_{2} \mathrm{CO}_{3}(81 \mathrm{mg}, 0.25 \mathrm{mmol})$ and $\mathrm{Pd}(\mathrm{dppf}) \mathrm{Cl}_{2}$ (16 mg, $\left.0.02 \mathrm{mmol}\right)$ in $3 \mathrm{~mL}$ of $4: 1: 4$ acetone $/ \mathrm{H}_{2} \mathrm{O} /$ toluene was heated in a Biotage Initiator microwave synthesizer at $140{ }^{\circ} \mathrm{C}$ for $30 \mathrm{~min}$. The resulting mixture was purified by flash chromatography to give $\mathbf{5 a}(24 \mathrm{mg})$ in $67 \%$ yield.

\section{Typical procedure for cyclocondensation of $4 \mathbf{e}, \mathbf{f}$.}

Synthesis of methyl 3,7-dimethyl-5-(3-(perfluorooctylsulfonyloxy)phenyl)- $5 \mathrm{H}$-thiazolo[3,2-a]pyrimidine-6-carboxylate (8b)

A solution of 3,4-dihydropyrimidinethione $4 \mathbf{f}(0.76 \mathrm{~g}, 1 \mathrm{mmol})$, chloroacetone (185 mg, $1.5 \mathrm{mmol}$ ) in $2 \mathrm{~mL}$ water was heated in Biotage Initiator microwave synthesizer at $120^{\circ} \mathrm{C}$ for $30 \mathrm{~min}$. The resulting mixture was purified by F-SPE eluted with $30 \mathrm{~mL}$ of 80:20 MeOH/ $\mathrm{H}_{2} \mathrm{O}$ and then $30 \mathrm{~mL}$ of acetone. The acetone fraction was concentrated to give $\mathbf{8 b}(0.67 \mathrm{~g})$ in $85 \%$ yield.

Typical Liebeskind-Srogl reaction procedure. Synthesis of methyl 4-methyl-6-(3-(perfluorooctylsulfonyloxy)phenyl)-2-phenyl-1,6-dihydropyrimidine-5carboxylate (9)

A solution of 3,4-dihydropyrimidinethione $4 \mathbf{f}(152 \mathrm{mg}, 0.20$ $\mathrm{mmol}$ ), phenylboronic acid ( $82 \mathrm{mg}, 0.3 \mathrm{mmol}), \mathrm{CuTC}$ (95 mg, $0.6 \mathrm{mmol})$, and $\mathrm{Pd}\left(\mathrm{PPh}_{3}\right)_{4}(3 \mathrm{~mol} \%)$ in $2 \mathrm{~mL}$ THF was heated in Biotage Initiator microwave synthesizer at $100{ }^{\circ} \mathrm{C}$ for 25

Table 3: Synthesis of 2-aryl-6-biaryl-substituted dihydropyrimidines.<smiles>COC(=O)C1=C(C)NC(=S)NC1c1cccc(OC(F)(F)F)c1</smiles>

$\mathrm{PhB}(\mathrm{OH})_{2}$ $\overrightarrow{\mathrm{Pd}\left(\mathrm{PPh}_{3}\right)_{4}, \mathrm{CuTC}}$ MW $100^{\circ} \mathrm{C}, 25 \mathrm{~min}$ F-SPE $76 \%$<smiles>COC(=O)C1=C(C)N=C(c2ccccc2)NC1c1cccc(OC(C)(F)F)c1</smiles><smiles>[Y]C1=C(C(=O)OC)C(c2cccc(-c3ccccc3)c2)NC(c2ccccc2)=N1</smiles>

$\mathrm{R}^{3}$

$\mathrm{H}$

$p-\mathrm{OCH}_{3}$

$m-\mathrm{Cl}$

$p-\mathrm{CH}_{3}$

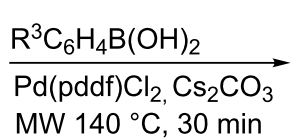

7 (yield)

$7 a(45 \%)$

$7 b(48 \%)$

$7 \mathrm{c}(31 \%)$

$7 \mathrm{~d}(48 \%)$ 
min. The mixture was purified by F-SPE eluted with $30 \mathrm{~mL}$ of $80: 20 \mathrm{MeOH} / \mathrm{H}_{2} \mathrm{O}$ and then $30 \mathrm{~mL}$ of acetone. The acetone fraction was concentrated to give $9(0.85 \mathrm{~g})$ in $76 \%$ yield.

\section{Supporting Information}

\section{Supporting Information File 1}

LC-MS, ${ }^{1} \mathrm{H}$ NMR and ${ }^{13} \mathrm{C}$ NMR data and spectra for compounds 4c, 5a, 6b, 7b, 8b, 9.

[http://www.beilstein-journals.org/bjoc/content/ supplementary/1860-5397-7-150-S1.pdf]

\section{Acknowledgments}

This work was supported by the Healey grant from University of Massachusetts Boston. We would like to thank Dave York for his participation in some initial experiments of this project.

\section{References}

1. Kappe, C. O. Acc. Chem. Res. 2000, 33, 879-888. doi:10.1021/ar000048h

2. Kappe, C. O. Eur. J. Med. Chem. 2000, 35, 1043-1052. doi:10.1016/S0223-5234(00)01189-2

3. Biginelli, P. Gazz. Chim. Ital. 1893, 23, 360-416.

4. Kappe, C. O.; Stadler, A. Org. React. 2004, 63, 1-116. doi:10.1002/0471264180.or063.01

5. Kappe, C. O. The Biginelli Reaction. In Multicomponent Reactions; Zhu, J.; Bienaymé, H., Eds.; Wiley-VCH: Weinheim, Germany, 2005; pp 95-120.

6. Studer, A.; Jeger, P.; Wipf, P.; Curran, D. P. J. Org. Chem. 1997, 62, 2917-2924.

7. Zhang, W.; Curran, D. P. Tetrahedron 2006, 62, 11837-11865. doi:10.1016/j.tet.2006.08.051

8. Larhed, M.; Hallberg, A. J. Org. Chem. 1996, 61, 9582-9584. doi:10.1021/jo9612990

9. Larhed, M.; Hoshino, M.; Hadida, S.; Curran, D. P.; Hallberg, A. J. Org. Chem. 1997, 62, 5583-5587. doi:10.1021/jo970362y

10. Kadam, A.; Zhang, Z.; Zhang, W. Curr. Org. Synth. 2011, 8, 295-309. doi:10.2174/157017911794697259

11.Zhang, W. Chem. Rev. 2009, 109, 749-795. doi:10.1021/cr800412s

12. Zhang, W. Comb. Chem. High Throughput Screening 2007, 10, 219-229.

13. Zhang, W.; Chen, C. H.-T.; Lu, Y.; Nagashima, T. Org. Lett. 2004, 6, 1473-1476. doi:10.1021/ol0496428

14. Kappe, C. O.; Dallinger, D. Nat. Rev. Drug Discovery 2006, 5, 51-63. doi:10.1038/nrd1926

15. Dallinger, D.; Kappe, C. O. Nat. Protoc. 2007, 2, 1713-1721. doi:10.1038/nprot.2007.224

16. Wang, X.-C.; Quan, Z.-J.; Zhang, Z.; Liu, Y.-J.; Ji, P.-Y. Lett. Org. Chem. 2007, 4, 370-373. doi:10.2174/157017807781212139

17. Quan, Z.-J.; Zhang, Z.; Wang, J.-K.; Wang, X.-C.; Liu, Y.-J.; Ji, P.-Y. Heteroat. Chem. 2008, 19, 149-152. doi:10.1002/hc.20386

18. Liebeskind, L. S.; Srogl, J. J. Am. Chem. Soc. 2000, 122, 11260-11261. doi:10.1021/ja005613q

19. Villalobos, J. M.; Srogl, J.; Liebeskind, L. S. J. Am. Chem. Soc. 2007, 129, 15734-15735. doi:10.1021/ja074931n
20. Prokopcová, H.; Kappe, C. O. J. Org. Chem. 2007, 72, 4440-4448. doi:10.1021/jo070408f

21. Prokopcová, H.; Kappe, C. O. Angew. Chem., Int. Ed. 2009, 48, 2276-2286. doi:10.1002/anie.200802842

\section{License and Terms}

This is an Open Access article under the terms of the Creative Commons Attribution License

(http://creativecommons.org/licenses/by/2.0), which permits unrestricted use, distribution, and reproduction in any medium, provided the original work is properly cited.

The license is subject to the Beilstein Journal of Organic Chemistry terms and conditions:

(http://www.beilstein-journals.org/bjoc)

The definitive version of this article is the electronic one which can be found at: doi: $10.3762 /$ bjoc. 7.150 